\title{
Is conditional conservatism a source of deviations of financial statements from
}

\author{
Benford's Law?
}

\author{
Tri T Nguyen, Chau M Duong, and Nguyet T M Nguyen *
}

\begin{abstract}
Purpose - In this paper, we examine the association between conditional conservatism and deviations of the first digits of financial statement items from what are expected by Benford's Law.
\end{abstract}

Design/methodology/approach - This research uses data of companies listed on the London Stock Exchange. We measure deviations of first digits from Benford's Law following Amiram et al. (2015) and firm-year conditional conservatism following previous studies (Basu, 1997; Khan and Watts, 2009; García Lara et al., 2016). We use multiple regressions to provide evidence for our hypothesis.

Findings - The results show that conditional conservatism is positively associated with deviations from Benford's Law. The findings are robust across different measures of deviations and conditional conservatism. Also, we find that the relationship between deviations from Benford's Law and conditional conservatism is more pronounced for firms with debt issuance, and for leveraged firms facing financial distress. Next, our analyses confirm previous evidence by showing that the first digits of financial statement items of UK listed companies conform to Benford's Law at the firm-specific level and the market level, and deviations of income statements are larger than those of balance sheets and cash flow statements.

Research limitations/implications - The research makes significant contributions to the literature. First, this is the first study that provides empirical evidence suggesting conditional conservatism may be a source of deviations from Benford Law. Second, we provide evidence confirming previous US findings (e.g., Amiram et al., 2015) showing that the distributions of first digits of financial statement items of UK listed companies also conform to Benford's Law.

Practical implications - Our findings have implications for auditors. Auditors should be aware of "false positive" for material misstatements when using Benford's Law as a risk assessment procedure. While both conditional conservatism and earnings management are related to deviations from Benford's Law, conservatism-related biases could indicate less audit risks.

\footnotetext{
* Tri Tri Nguyen is from University of Brighton (United Kingdom) and University of Economics Ho Chi Minh City (Vietnam). Chau Minh Duong is from University of East London (United Kingdom) and Ho Chi Minh City Open University (Vietnam). Nguyet Thi Minh Nguyen is from University of Roehampton (United Kingdom). We are thankful to Othmar Lehner, the Editor, and the two anonymous reviewers for their valuable comments and suggestions. We gratefully acknowledge Mark Nigrini, Sunitha Narendran, John Chandler, Thai Quoc Nguyen and participants at British Accounting and Finance Association's Annual Conference 2019 and seminars at University of East London and University of Brighton for their helpful feedback on previous versions of the paper. All errors are the authors.

Authors' contact information: Tri Tri Nguyen (Corresponding author): t.nguyen2@brighton.ac.uk, School of Business and Law, University of Brighton, Elm House, Lewes Road, Brighton BN2 4AT. Chau Minh Duong: c.duong@uel.ac.uk. Nguyet Thi Minh Nguyen: nguyet.nguyen@roehampton.ac.uk.
} 
Originality/value - We provide new and original evidence suggesting that conditional conservatism is related to deviations from Benford's Law.

Keywords - Benford's Law, earnings management, conditional conservatism

Paper type - Research paper 


\section{Introduction}

Benford's Law refers to the distributional probability of the digits of numbers in a data set. The law indicates that every digit will appear with a certain frequency in the data set. Deviations from the expected frequencies are indications of the existence of biases, e.g. unintentional errors or deliberate alteration, in data sets. Researchers have applied Benford's Law to accounting numbers to study biases that may be caused by intentional or unintentional acts. For example, Benford's Law can be applied to examine biases in the interest received and interest paid lines on individual tax returns (Nigrini, 1996) or rounding up behaviours (Carslaw, 1988; Thomas, 1989). Recently, Amiram et al. (2015) develop a methodology that uses firmyear financial statements to calculate deviations from Benford's Law to study errors, e.g. earnings management, in financial statement data. The authors use ameasure of deviations, namely FSD score which measures the mean absoluate deviation of the distribution of the first digits of numbers reported in financial statements from the expected distrbution under Benford's Law. Amiram et al. (2015) prove that an introduction of errors in financial statements results in higher FSD score, which is the deviation of financial statement items from Benford's Law. They also find that FSD score is associated with discretionary accruals, a proxy for earnings management, making this measure helpful to predict material accounting misstatements identified by accounting and auditing enforcement releases (AAERs) issued by the US Securities and Exchange Commission.

In general, the previous research shows that biases, either resulted from deliberate earnings management or unintentional errors, is a source of deviations of financial statement data from Benford's Law. However, to the best of our knowledge, no prior research has offered an alternative explanation for such deviations. Therefore, in this research, we investigate whether conditional conservatism may be a source of deviations from Benford's Law. 
Conditional conservatism refers to the understatement of asset values by allowing financial statements to record losses in unfavourable circumstances but not gains in favourable circumstances (Basu, 1997; Watts, 2003a, 2003b). Conditional conservatism is newsdependent and requires managerial judgement to record losses in unfavourable conditions. Mora and Walker (2015) explain that conditional conservatism is controversial because it facilitates earnings management practices, such as downward earnings management, by recognising huge losses to create reserves for future use. There is also empirical evidence that managers choose different levels of conditional conservatism depending on specific circumstances in order to deceive boards of directors and influence their decisions (Caskey and Laux, 2017), deal with litigation risk (Basu and Liang, 2019), deal with problems arising from information asymmetry (LaFond and Watts, 2008; Goh et al., 2017), or provide lenders with an assurance of timely signals of their creditworthiness to get benefits from lower interest rates (Zhang, 2008). The literature also provides evidence that the level of conditional conservatism is affected by the gender of directors and ethical leadership (Francis et al., 2015; Ho et al., 2015; Al-Shaer and Harakeh, 2020).

In general, the literature shows that managers can exercise discretion over financial statements by using different levels of conditional conservatism to affect organisational outcomes. Therefore, we hypothesise that conditional conservatism is related to biases in financial statements, leading to higher deviations of the first digits of numbers reported in financial statements from Benford's Law.

We test our main hypothesis using a sample of UK listed companies from 2005 to 2012 . We measure deviations of first digits from Benford's Law by using the FSD score following Amiram et al. (2015), which is the mean absolute differences between expected frequencies and actual frequencies of the first digits of financial statement items. We estimate firm-year conditional conservatism following previous studies (Basu, 1997; Khan and Watts, 2009; 
García Lara et al., 2016). The results show that conditional conservatism is positively associated with deviations from Benford's Law. The association is statistically significant at 1 percent level. The findings hold strongly for different measures of deviations and conditional conservatism. Next, the results indicate that the relationship between conditional conservatism and devations from Benford's Law is more pronounced for firms with debt issuance and for leveraged firms facing financial distress. Moreover, our analyses confirm previous evidence (e.g., Amiram et al., 2015) by showing that the first digits of financial statement items of UK listed companies conform to Benford's Law at the firm-specific level and the market level. We also find that the deviations are larger in income statements than in balance sheets and cash flow statements.

The research makes significant contributions to the literature and practice. First, we are the first to offer an alternative explanation for deviations of first digits. The existing literature explains that the first digits deviate from Benford's Law because biases such as fraud or earnings management exist in financial statements (e.g., Caneghem, 2002, 2004; Amiram et al., 2015). Our research shows that conditional conservatism is positively related to first-digit deviations, suggesting that conditional conservatism may also be a source of deviation. Second, we provide evidence to confirm the previous findings (e.g., Amiram et al., 2015) that the first digits of financial statement items follow Benford's Law, by using data from a different context (UK data). We note that our research is different from the work of Caneghem (2002) and Caneghem (2004), which examine the effect of earnings managmeent on the deviations of second digits of profits or losses (earnings) from Benford's Law. By studying all figures reported in financial statements, we account for the fact that biases may exist not only in reported earnings numbers 
but also in individual items of financial statements such as assets, liabilities, incomes, expenses, and cash flows. ${ }^{2}$

Our paper proceeds as follows. Section 2 provides a literature review and hypothesis development. Section 3 explains our research methodologies, including sample selection and empirical model. Section 4 presents the main regression results, followed by robustness checks in Section 5, cross-sectional analyses in Section 6, and additional analyses in Section 7. Section 8 provides the concluding remarks of our paper.

\section{Literature review and hypothesis development}

\subsection{Benford's Law in accounting research}

Benford's Law refers to the distributional probability of the digits of numbers in a data set. The distributional probability of first digits was discovered by astronomer Simon Newcomb in 1881 and was later tested on various data sets by physicist Frank Benford, who gave Benford's Law its name (Amiram et al., 2015). The expected frequencies of the first digits of numbers in a data set are presented in Table 1 (Amiram et al., 2015, p. 1547): ${ }^{3}$

Table 1: The expected frequencies of the first digits of numbers

\begin{tabular}{|l|l|l|l|l|l|l|l|l|l|}
\hline First digit & 1 & 2 & 3 & 4 & 5 & 6 & 7 & 8 & 9 \\
\hline $\begin{array}{l}\text { Expected } \\
\text { frequency }\end{array}$ & 0.301 & 0.176 & 0.125 & 0.097 & 0.079 & 0.067 & 0.058 & 0.051 & 0.046 \\
\hline
\end{tabular}

\footnotetext{
${ }^{2}$ Our approach is in line with the standard setters' view that the general purpose of financial statements is to present financial information for different users, including shareholders, debtholders and others such as employees, suppliers, customers and government (International Accounting Standards Board (IASB), 2018). Different users may require different types of accounting information. Also, the Conceptual Framework (IASB, 2018) firstly defines assets and liabilities (balance sheet items), and then incomes and expenses (income statement items) are defined based on changes in assets and liabilities. The interpretation is that assets and liabilities are cornerstones of financial statements and changes in assets and liabilities will affect reported earnings. While income statement items (including net income) are possibly the most important figures for shareholders, balance sheet items may also be important because they provide debtholders with information on the financial health of companies.

${ }^{3}$ The distribution of the first and other digits can also be presented in mathematical forms (see, e.g., Carslaw, 1988; Thomas, 1989; Nigrini, 1996; Amiram et al., 2015; Nigrini, 2015).
} 
The reason that the probability of the first digit being 1 is the greatest and the probability of the first digit being 9 is the smallest is as follows. As explained by Nigrini (1996), the number 1 needs $100 \%$ growth to change to the number 2 (e.g., if the population of a city increases from 100,000 to 200,000 ), the number 2 needs only $50 \%$ growth to change to the number 3 , and so forth, until finally, the number 9 , which needs only $11.1 \%$ growth to change to the number 1 . Therefore, a number starting with the digit 1 (9) has the greatest (smallest) probability of existence in a population.

A common application of Benford's Law is to assess the conformity of accounting numbers to Benford's Law in tabulated (actual) data. Nigrini (1994) indicates that non-conformity to Benford's Law may be a red flag for biases (or errors) in data. From a practical perspective, Nigrini and Mittermaier (1997) propose that comparing actual and expected frequencies of a list of numbers can be used as an analytical procedure in an audit engagement. Durtschi et al. (2004) also provide guidance for auditors to apply Benford's Law to detect suspected accounts that may contain fraud instances. Da Silva and Carreira (2013) use predefined criteria based on Benford's Law to develop models that support auditors in constructing audit samples containing conforming and non-conforming transactions.

Empirical research in accounting has explored Benford's Law to examine earnings management. For example, studying the interest received and interest paid lines on individual tax returns, Nigrini (1996) report that the interest received line has higher (lower) than expected frequencies of smaller (larger) first digits. In contrast, the interest paid line has lower (higher) than expected frequencies of smaller (larger) first digits. The findings suggest that interest received (paid) is understated (overstated) due to taxpayers intentionally evading tax.

Carslaw (1988) studies the second digits of reported incomes in financial statements of New Zealand firms and find that the actual frequencies of $0 \mathrm{~s}(9 \mathrm{~s})$ are higher (lower) than those 
expected by Benford's Law. He theorises that this phenomenon is caused by the tendency of managers to round numbers up to achieve earnings targets. For example, when an earnings target is 6,000 but the true earnings is 5,984 (or any number just below 6,000), managers are more likely to report the earnings number as 6,004 (or any number just above 6,000) to meet or beat the earnings target. Consequently, the frequency of second-digit 0s will be abnormally high, while the frequency of second-digit 9s will be abnormally low.

Consistent with Carslaw (1988), Thomas (1989) shows similar patterns in the US, but with less deviation of earnings numbers from the expectations following Benford's Law. Thomas (1989) also reports that while firms showing losses have more second-digit 9s and fewer second-digit 0s than expected, companies showing profits have abnormally high frequencies of second-digit 0s and 5s (after the decimal points) in their earnings-per-share (EPS) numbers. Later studies provide further evidence supporting the notion that the second digits of earnings numbers do not follow Benford's Law as a result of rounding-up behaviour (e.g., Niskanen and Keloharju, 2000; Caneghem, 2002, 2004).

Studying first digits rather than second digits, Amiram et al. (2015) develop an innovative score, namely the FSD, to capture deviations from Benford's Law of the first digits of figures reported in financial statements. The FSD is defined as the sum of first-digit deviations from Benford's Law divided by nine, where deviations are absolute differences between observed (actual) frequencies of the first digits and the expected frequencies of all items in balance sheets, income statements, and cash flow statements. Amiram et al. (2015) prove that an introduction of biases, e.g. errors, in financial statements results in more divergences of first digits from Benford's Law. The FSD is also associated with earnings management, which makes this measure helpful to predict material accounting misstatements identified by 
accounting and auditing enforcement releases, or AAERs, issued by the US Securities and Exchange Commission.

Similar to the approach of Amiram et al. (2015), Nigrini (2015) relies on the law of the first two digits to study the conformity to Benford's Law of accounting data, stock prices and trading volumes of US companies. To capture deviations of the first two digits, Nigrini (2015) also uses the mean absolute deviations, which is the sum of the absolute difference between expected frequencies and actual frequencies of the first two digits divided by 90 (which is the number of possible two-digit combinations between 10 to 99). The author shows that distributions of the first two digits of accounting data, stock prices, and trading volumes closely conform to Benford's Law.

In the context of the UK, there are relatively few accounting studies applying Benford's Law. Caneghem (2002) and Caneghem (2004) find that there is an abnormally high (low) frequency of the second-digit $0 \mathrm{~s}(9 \mathrm{~s})$ in income numbers, and these deviations of second-digit $0 \mathrm{~s}(9 \mathrm{~s})$ from what is expected by Benford's Law are statistically significant. Highly abnormal distributions do not exist in other second digits. This evidence is consistent with previous studies on rounding-up behaviour (Carslaw, 1988; Thomas, 1989; Niskanen and Keloharju, 2000; Caneghem, 2002). Caneghem (2002) attempts to explain the causes of deviations from Benford's Law of earnings numbers. Using abnormal accruals as a proxy for earnings management, he indicates that firms that are involved in the rounding up of earnings exhibit higher discretionary accruals. The evidence suggests that firms are likely to manage accruals to achieve targeted earnings and the introduction of earnings management results in significant variations of the second digits to Benford's Law. The notion that earnings management is related to deviations from Benford's Law is also supported by the findings of Amiram et al. (2015). However, while Amiram et al. (2015) study the first digits of all figures reported in 
financial statements, Caneghem (2002) examines the distribution of the second digits of earnings numbers.

In another research, Caneghem (2004) studies the effect of audit quality on deviation from Benford's Law, which results from the rounding up of the second digits of earnings figures. He uses deviations of second-digit $0 \mathrm{~s}$ and $9 \mathrm{~s}$ of pre-tax earnings as a proxy for earnings management. Contrary to evidence on the effect of audit quality on earnings management (Krishnan, 2003), Caneghem (2004) finds that the abnormal distributions of second-digit 0s and 9s are not statistically significantly different between companies audited by the Big Four firms and companies audited by non-Big Four firms.

\subsection{Benefits and costs of conditional conservatism}

Accounting conservatism refers to accounting practises that reduce a company's net book value of asset relative to its "real economic value" (Financial Accounting Standards Board, 1980; International Accounting Standards Committee, 1989). From the accounting standard setters, accounting conservatism is necessary to cope with potential earnings volatility. Thus, the goal of accounting conservatism is to avoid overstating earnings and asset values. Similarly, Watts and Zimmerman (1990) describe accounting conservatism as predetermined accounting policy choices that result in the lowest (highest) asset values (liabilities).

Based on the above definitions, there are two forms of accounting conservatism: unconditional and conditional conservatism (Ball and Shivakumar, 2005; Beaver and Ryan, 2005). Unconditional conservatism refers to accounting treatments that result in lower book values compared to neutral (economic) values of net assets; it is also known as "balance sheet conservatism" or "news-independent conservatism" since it is not influenced by news. 4

\footnotetext{
${ }^{4}$ Mora and Walker (2015) explain two causes of unconditional conservatism. First, unconditional conservatism arises from the conservative recognition of financial statement items that do not meet definitions of recognition criteria, e.g. research-stage expenditures are not allowed to be capitalised. Second, unconditional conservatism also arises from conservative measurement of assets, e.g. fixed assets are depreciated at
} 
Conditional conservatism applies to the understatement of asset values by allowing financial statements to record losses in unfavourable circumstances but not gains in favourable circumstances. Conditional conservatism refers to how fast bad and good news are reported in financial statements, and it is also known as news-dependent conservatism. In a seminal work, Basu (1997) defines conditional conservatism as "the accountant's tendency to require a higher degree of verification to recognise good news as gains than to recognise bad news as losses". Positive news needs a higher degree of verification than negative news. This is the asymmetric recognition of bad news over good news, which contributes to conservatism. ${ }^{5,6}$

In this study, we focus on conditional conservatism because it depends significantly on managerial discretion. While some studies document the informational benefits of conditional conservatism, other studies raise concerns that conditional conservatism induces downward earnings management. On the one hand, empirical studies show that conditional conservatism is beneficial for both lenders and shareholders. Together with debt covenants, conditional conservatism is a debt monitoring mechanism because it results in lower asset values, which provide lenders with an early indication about the creditworthiness of borrowers (e.g., Nikolaev, 2010). Conditional conservatism helps lenders more efficiently monitor borrowers' ability to pay, thus reduces the cost of debt (Ahmed et al., 2002; Zhang, 2008). In a principalagent framework (agency theory), conditional conservatism is useful to minimise agency costs when penalties for wrongful acts of agents are limited and when agents make suboptimal decisions (Kwon et al., 2001; Kwon, 2005). LaFond and Watts (2008) find a negative

\footnotetext{
a rate higher than the "economic rate of depreciation," which is the rate at which the book value of fixed assets is equal to their economic value.

${ }^{5}$ An example of conditional conservatism is the requirement that inventory is calculated at the lower value between historical cost and net realisable value. This requirement results in recognition of losses when there is bad news about inventory but not in recognition of gains when there is good news.

${ }^{6}$ García Lara et al. (2020) explains that conditional conservatism is conceptually different from earnings management, e.g., income-decreasing earnings management. Conditional conservatism recognises present economic losses that will occur in the future. As a result, it is not an income-decreasing type of earnings management, and it should not be confused with the deliberate overstatement of economic losses, income smoothing, or the news-unrelated recognition of losses due to extreme prudence.
} 
relationship between conditional conservatism and managerial ownership, suggesting that more conditional conservatism is needed as a managerial control when managerial ownership decreases. The accounting literature also documents that conditional conservatism helps to address investors' concerns about the uncertainty of future firm value, thus reduces the cost of equity as well as the volatility and crash risk of stock prices (Suijs, 2008; García Lara et al., 2011; Francis et al., 2013; Kim and Zhang, 2016; Goh et al., 2017).

On the other hand, there is empirical evidence that conditional conservatism is costly for firms. Li (2013) proposes a theoretical model showing that conservative accounting decreases the debt contract efficiency in several circumstances, e.g. when covenant renegotiation is not feasible or is induced by extremely high costs. Heflin et al. (2015) and Kravet (2014) provide direct empirical evidence on the unintended effects of conditional conservatism. According to Heflin et al. (2015), conditional conservatism causes reported earnings less informative for stock valuation. The authors find that conditional conservatism negatively impacts earnings persistence and informativeness. Kravet (2014) shows that conditional conservatism prohibits managers from making risky investments that could result in large returns for shareholders.

\subsection{Conditional conservatism and Benford's Law}

So far, the literature documents that Benford's Law has been useful in examining biases in data sets. The literature also shows that earnings management results in deviations of financial statements from Benford's Law. However, there have been few attempts to provide an alternative explanation for such deviations. Motivated by current debates on conditional conservatism, we further examine whether it can be a source of deviations from Benford's Law.

As explained above, conditional conservatism is news-dependent and requires managerial judgement to record losses in unfavourable conditions. Mora and Walker (2015) explain that conditional conservatism is controversial because it facilitates earnings management practices, 
such as downward earnings management, by recognising large losses to create reserves for future use. There is also empirical evidence that managers choose different levels of conditional conservatism depending on specific circumstances. For example, Ramanna and Watts (2012) show that managers have private incentives to influence unverifiable estimates such as goodwill impairment. Caskey and Laux (2017) indicate that conservatism allows managers to engage in earnings management to influence the decisions made by boards of directors. Managers reduce conditional conservatism when there is a decrease in litigation risk for nonexecutive directors (Basu and Liang, 2019). Recently, Burke et al. (2020) find a negative association between conditional conservatism and corporate social responsibility (CSR) rating, suggesting that managers provide less conservative financial statements because the demand for conditional conservatism decreases following an increase in CSR activities. Managers may report different levels of conditional conservatism to deal with problems arising from information asymmetry between insiders and outsiders (LaFond and Watts, 2008), between shareholders and debtholders (Goh et al., 2017), or to provide lenders with an assurance of timely signals of their creditworthiness to get benefits from lower interest rates (Zhang, 2008). Next, the literature provides evidence that the level of conditional conservatism is related to the gender of directors and ethical leadership (Francis et al., 2015; Ho et al., 2015; Al-Shaer and Harakeh, 2020). ${ }^{7}$

In general, the accounting literature documents that managers can exercise discretion over financial statements by using different levels of conditional conservatism to affect organisational outcomes. Therefore, we hypothesise that conditional conservatism is related to

\footnotetext{
${ }^{7}$ Recently, Lin et al. (2014) use deviations of digits of quarterly net income from Benford's Law as a measure of earnings management and find that firms with higher conservatism exhibit lower earnings management, but the findings also indicate that managers of firms with higher conservatism have more incentives to manipulate earnings in the presence of institutional shareholders. This mixed evidence also contributes to the controversy. In this paper, we study deviations of first digits of all items reported in annual, rather than quarterly, financial statements to examine whether conservatism is a source of deviations.
} 
biases in financial statements, which leads to higher deviations of first digits from Benford's Law. We present our hypothesis in an alternative form as follows.

H1: Conditional conservatism is positively associated with deviations of first digits of financial statement items from what are expected by Benford's Law.

\section{Research methodologies}

\subsection{Sample selection}

Our research uses data of all companies listed on the London Stock Exchange from 2005 to 2012. ${ }^{8}$ We download all financial statements items from the Datastream database. ${ }^{9}$ Financial institutions and utility firms are removed. We replace missing values with 0 s when calculating the distributions of first digits, but this approach does not affect the analysis because 0 cannot be a leading digit. We extract the first digits of financial statement items (including balance sheets, income statements and cash flow statements). For negative numbers, we use the first digit after the negative sign. For numbers from -1 to 1 , we use the first non-zero digit. Finally, we remove observations with fewer than 50 total first digits because the inclusion of firms with few total first digits may introduce bias to the sample. ${ }^{10}$ This process results in 10,048 firmyear observations from 2005 to 2012 (1,839 unique companies) with 721,027 first digits. ${ }^{11}$ Finally, we derive a sample of 3,635 firm-year observations with sufficient data for our main regressions. All continuous variables are winsorised to the $1^{\text {st }}$ and $99^{\text {th }}$ percentiles.

\footnotetext{
${ }^{8}$ We start the sample in 2005 to avoid the effect of IFRS adoption (2005) on conditional conservatism and end in 2012 to avoid the effect of new corporate governance guidance in the UK.

${ }^{9}$ It is common that researchers study Benford's Law using financial data obtained from databases such as Compustat (Amiram et al., 2015; Nigrini, 2015), Bureau van Dijk's Amadeus CD-ROM (Caneghem, 2002, 2004). Mukherjee (2017) also use compensation data from ExecuComp database.

${ }^{10}$ Amiram et al. (2015) indicate that firms with fewer first digits may be too young or not in continuing operations, therefore including those firms may cause measurement errors. While Amiram et al. (2015) dropped observations with less than 100 digits, we dropped observations with less than 50 digits to avoid a significant reduction in sample size, which might reduce the statistical inference.

${ }^{11}$ This sample is used for an additional analysis to test the conformity of financial statements of UK listed companies to Benford's Law.
} 


\subsection{Measure of deviations from Benford's Law}

We measure deviations from Benford's Law by employing the FSD score, developed by Amiram et al. (2015). We calculate FSD for each company in each year (firm-year observations) as follows:

$$
\mathrm{FSD}_{\mathrm{it}}=\frac{\sum_{\mathrm{d}=1}^{9} \mid \text { OBSERVED }_{\mathrm{dit}}-\text { EXPECTED }_{\mathrm{d}} \mid}{9}
$$

Where: $\mathrm{FSD}_{\mathrm{it}}$ is the mean absolute deviation of the first digits of financial statement items from that expected by Benford's Law of firm $\mathrm{i}$ in year $\mathrm{t}$; OBSERVED dit $_{\text {is }}$ the actual probability of the first digit $d$ of firm $i$ in year $t$; EXPECTED $d$ is the expected probability of the first digit $d$ following Benford's Law; and d =1,2, ., 9 .

\subsection{Measure of conditional conservatism}

We follow Khan and Watts (2009) and estimate firm-year conditional conservatism. The Khan and Watts (2009)'s model is based on Basu (1997). Specifically, we first run the following regression for each year:

$$
\begin{aligned}
& \text { EARN }_{i t}=\beta_{1}+\beta_{2} D_{i t}+\left(\mu_{1}+\mu_{2} \text { SIZE }_{i t-1}+\mu_{3} \text { MTB }_{i t-1}+\mu_{4} \mathrm{LEV}_{\text {it }-1}\right) \text { RET }_{i t}+ \\
& \left(\gamma_{1}+\gamma_{2} \text { SIZE }_{\text {it-1 }}+\gamma_{3} \text { MTB }_{\text {it }-1}+\gamma_{4} \mathrm{LEV}_{\text {it-1 }}\right) \mathrm{D}_{\mathrm{it}} * \mathrm{RET}_{\mathrm{it}}+ \\
& \left(\delta_{1} \mathrm{SIZE}_{\mathrm{it}-1}+\delta_{2} \mathrm{MTB}_{\mathrm{it}-1}+\delta_{3} \mathrm{LEV}_{\mathrm{it}-1}+\delta_{4} \mathrm{D}_{\mathrm{it}} * \mathrm{SIZE}_{\mathrm{it}-1}+\delta_{5} \mathrm{D}_{\mathrm{it}} * \mathrm{MTB}_{\mathrm{it}-1}+\delta_{6} \mathrm{D}_{\mathrm{it}}\right. \\
& \left.* \mathrm{LEV}_{\mathrm{it}-1}\right)+\varepsilon_{\mathrm{it}}
\end{aligned}
$$

$\mathrm{EARN}_{\text {it }}$ is net income before extraordinary items in year $\mathrm{t}$, scaled by the market value of equity at the end of year $\mathrm{t}-1$; RET $\mathrm{R}_{\text {it }}$ is buy-and-hold stock returns for fiscal year $\mathrm{t}$; $\mathrm{D}_{\text {it }}$ is a dummy variable either equal to 1 if $\operatorname{RET}_{i t}<0$, otherwise it is equal to 0 ; $\mathrm{SIZE}_{\mathrm{it}-1}$ is the natural $\log$ of the market value of equity at the end of year $\mathrm{t}-1$; $^{\mathrm{MTB}_{\mathrm{it}-1}}$ is the market-to-book ratio at the 
end of year $\mathrm{t}-1$; $\mathrm{LEV}_{\mathrm{it}-1}$ is the sum of long-term and short-term debts at the end of year $\mathrm{t}-1$, scaled by the market value of equity at the end of year $\mathrm{t}-1$.

We then calculate empirical measures of the timeliness of good news (GSCORE) and the incremental timeliness of bad news over good news (CSCORE) based on firm characteristics as follows: ${ }^{12}$

$$
\begin{aligned}
& \text { GSCORE }_{\text {it }}=\beta_{3}=\mu_{1}+\mu_{2} \text { SIZE }_{i t-1}+\mu_{3} \text { MTB }_{\text {it }-1}+\mu_{4} \text { LEV }_{\text {it }-1} \\
& \text { CSCORE }_{\text {it }}=\beta_{4}=\gamma_{1}+\gamma_{2} \text { SIZE }_{\text {it }-1}+\gamma_{3} \text { MTB }_{\text {it }-1}+\gamma_{4} \text { LEV }_{\text {it }-1}
\end{aligned}
$$

CSCORE is the measure of conditional conservatism, which captures the incremental timeliness of bad news over good news. We calculate the average of CSCORE across years t$2, t-1$ and $t$. We then calculate the annual fractional rank of accounting conservatism, denoted CSCORE_RANK, by ranking the average values of CSCORE for all observations by year and then dividing the ranked values by $\mathrm{N}+1$ (where $\mathrm{N}$ is the total number of observations in each year). We use ranked values because they help to mitigate concerns about nonlinearity and measurement errors (García Lara et al., 2016; Goh et al., 2017). ${ }^{13}$

\subsection{Empirical model}

\footnotetext{
${ }^{12}$ In this research, we used lagged values of firm characteristics while Khan and Watts (2009) use values at the end of current year. Because earnings are figures for an entire year, firms can rely on financial conditions at the beginning of the year to determine the needed levels of conservatism for the year. The use of lagged values of firm characteristics is supported by Ball et al. (2013a) and applied in recent studies (Banker et al., 2012; Nguyen et al., 2020).

${ }^{13}$ One may argue that there may be measurement errors in estimating accounting conservatism using Basu's (1997) model, which could be attributable to first-digit deviations. This argument is based on some evidence that the measure of accounting conservatism following Basu (1997) is biased (Pae et al., 2005; Dietrich et al., 2007; Givoly et al., 2007; Roychowdhury and Watts, 2007). However, there is emerging evidence for the validity of Basu's coefficient (Ball et al., 2013a; Ball et al., 2013b). For example, Ball et al. (2013b) explain that the Basu's model is criticised because the creator did not explain econometric foundations enough for its validity. Hsu et al. (2012) also support the validity of Basu's model. The Basu's model has been widely applied in recent years (e.g., Lobo et al., 2019; Muttakin et al., 2019; Dai and Ngo, 2020; Moy et al., 2020).
} 
To provide evidence for the relationship between conditional conservatism and deviations of the first digits of financial statement items from Benford's Law, we run the following regression (e.g. Amiram et al., 2015):

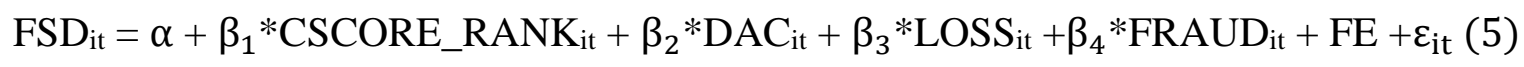

In equation (5), FSD $_{\text {it }}$ stands for deviations from Benford's Law (Amiram et al., 2015) of firm $\mathrm{i}$ in year t. CSCORE_RANK $\mathrm{it}_{\mathrm{t}}$ is the firm-year measure of conditional conservatism (Khan and Watts, 2009; García Lara et al., 2016). DAC is discretionary accruals estimated from the modified-Jones model (Jones, 1991; Dechow et al., 1995). LOSS is losses in previous years, which is equal to 1 if net incomes before extraordinary items in years $t-2$ and $t-1$ are both negative, 0 otherwise. FRAUD is based on the FSCORE following Dechow et al. (2011) (Model 1, Table 7) and is equal to 1 if FSCORE is greater than 1 , otherwise $0 .{ }^{14} \mathrm{We}$ also control for industry and year fixed effects (FE). ${ }^{15} \mathrm{We}$ provide full variable definitions in the Appendix.

We expect that $\beta_{1}$ would be positive and significant, consistent with our hypothesis $\mathrm{H} 1$. We also expect that $\beta_{2}, \beta_{3}$ and $\beta_{4}$ are positive and significant following previous studies (e.g., Amiram et al., 2015).

\section{Main regression results}

\subsection{Descriptive statistics and correlations}

Table 2 reports descriptive statistics of firm characteristics and selected variables. Firm characteristics are broadly similar to those used in prior research, which uses similar data (e.g., Goh and Gupta, 2016; Nguyen et al., 2020). The statistics show that the mean and standard

\footnotetext{
${ }^{14}$ In a robustness check, we further include another control, the natural logarithm of the number of first digits used to calculate FSD score of each firm in each year. Our findings (unreported) are qualitatively unchanged.

${ }^{15}$ In Equation (5), we do not control for other firm characteristics, such as firm size, financial leverage, and market-to-book ratio... to avoid multicollinearity concerns because CSCORE_RANK is estimated from these firm characteristics as specified in equation (2)-(4).
} 
deviation of FSD are 0.032 and 0.01 , respectively, which are comparable to those of US listed companies reported by Amiram et al. (2015). ${ }^{16}$ Next, the mean of discretionary accruals (DAC) is 0.080 , indicating that, on average, earnings are managed by $8 \%$ of opening total assets. The descriptive statistics also suggest that the sample has fewer firms with losses in two consecutive years (median of LOSS is 0) and has fewer firms with high risk of fraud (median of FRAUD is 0$)$.

[Insert Table 2 around here]

Table 3 shows the correlations of selected variables. The findings indicate that the correlation between FSD and CSCORE_RANK is positive and statistically significant, providing preliminary evidence to support hypothesis H1. Also, the correlation coefficients among the independent variables are very small (less than 0.2 ) and the VIF values are less than 1.3, suggesting that multicollinearity is not a significant concern.

[Insert Table 3 around here]

\subsection{Main regression results}

This section presents the main regression results for hypothesis $\mathrm{H} 1$ that conditional conservatism is positively associated with deviations of the first digits of financial statement items from what are expected by Benford's Law. As reported in Table 4, we find that FSD is positively related to CSCORE_RANK across all columns. The relationship is statistically significant at the $1 \%$ level. Moreover, the relationship between FSD and CSCORE_RANK is significant in economic terms. For example, in column [4], where we include all controls and fixed effects, we observe that one unit increase in conditional conservatism is associated with ${ }^{16}$ Amiram et al. (2015) report the mean and standard deviation of 0.029 and 0.0087 , respectively, for US listed companies for the period from
2001 to 2011 . 
an increase of 0.0042 in FSD, which accounts for $13 \%$ of FSD $(=0.0042 / 0.032)$, given that the mean of FSD is 0.032 (see Table 2).

[Insert Table 4 around here]

Regarding control variables, we find a positive and significant relationship between FSD and discretionary accruals (DAC). The findings are consistent with the notion that accruals-based earnings management causes deviations of digits of accounting numbers from Benford's Law (Caneghem, 2002, 2004; Durtschi et al., 2004; Amiram et al., 2015). Higher discretionary accruals are associated with larger FSD because when earnings are managed, the first digits of financial statement items deviate from the expectations of Benford's Law. Also, we find that FSD is higher for firms with losses in two consecutive years (LOSS =1), consistent with prior studies (e.g., Amiram et al., 2015).

In general, we find evidence in support of hypothesis H1, suggesting that conditional conservatism may be a source of first-digit deviations.

\section{Robustness checks}

In this section, we perform two robustness checks to mitigate the concerns that the relationship between deviation from Benford's Law and conditional conservatism is sensitive to empirical measurement choices.

\subsection{An alternative measure of the deviation from Benford's Law}

First, we calculate the deviation from Benford's Law in a different way. In particular, we follow Amiram et al. (2015) and calculate the maximum cumulative absolute deviation of the first digits of items reported in financial statements from that expected by Benford's Law (KS value) as follows: 


$$
\begin{aligned}
\mathrm{KS}_{\text {it }}=\max \{\mid & O D_{1 \mathrm{it}}-\mathrm{ED}_{1}|,|\left(\mathrm{OD}_{1 \mathrm{it}}+O \mathrm{OD}_{2 \mathrm{it}}\right)-\left(\mathrm{ED}_{1}\right. \\
& \left.+\mathrm{ED}_{2}\right)|, \ldots,|\left(\mathrm{OD}_{1 \mathrm{it}}+\mathrm{OD}_{2 \mathrm{it}}+\cdots+\mathrm{OD}_{9 \mathrm{it}}\right)-\left(\mathrm{ED}_{1}+\mathrm{ED}_{2}+\cdots\right. \\
& \left.\left.+\mathrm{ED}_{9}\right) \mid\right\}
\end{aligned}
$$

Where $\mathrm{KS}_{\mathrm{it}}$ is the maximum cumulative absolute deviation of the first digits of items reported in financial statements from that expected by Benford's Law of firm $\mathrm{i}$ in year $\mathrm{t}$; $\mathrm{OD}_{\mathrm{dit}}$ is the cumulative observed probability of the first digit $d(d=1,2, \ldots, 9)$ of firm $i$ in year $t ; D_{d}$ is the expected probability of the first digit $d(d=1,2, \ldots, 9)$, as defined by Benford's Law.

We rerun equation (5) where the dependent variable is $\mathrm{KS}$ values. As reported in Panel A of Table 5, we also find a positive and significant association between KS and CSCORE_RANK. The result is consistent with the main results.

[Insert Table 5 around here]

\subsection{An alternative measure of conservatism}

In the second robustness check, we use an alternative measure of conditional conservatism. We use total conservatism, which is the sum of GSCORE (timeliness of good news) and CSCORE (incremental timeliness of bad news over good news) obtained from equations (2)-(4) above (Basu, 1997; Khan and Watts, 2009; García Lara et al., 2016), denoted CONS (total timeliness of bad news). We calculate the ranked values of total conservatism (CONS_RANK) in the same way with CSCORE_RANK. We rerun equation (5) by substituting CSCORE_RANK for CONS_RANK. As reported in Panel B of Table 5, we also find a positive and significant relationship between FSD score and CONS_RANK, confirming our main results.

\section{Cross-sectional analyses}


In this section, we perform cross-sectional analyses to provide corroborating finding to support our main hypothesis.

\subsection{Debt issuance}

As explained earlier, conditional conservatism functions as a debt monitoring tool since it results in reduced asset values, which give lenders an early indicator of a borrower's creditworthiness (e.g., Zhang, 2008; Nikolaev, 2010). In addition, conditional conservatism enables lenders to monitor borrowers' capacity to pay more effectively, lowering the cost of debts (Ahmed et al., 2002; Zhang, 2008). Therefore, because of the monitoring role played by debtholders, debt issuance is often associated with higher conditional conservatism, which in turn leads to higher deviations of first digits from Benford's Law. We, therefore, expect that given the same level of conditional conservatism, firms with debt issuance should exhibit greater deviations from Benford's Law.

To test the above prediction, we create the variable DEBT, which is a dummy variable that takes a value of 1 if an increase in total debts from year $t-1$ to year $t$ is greater than or equal to 5 percent of total debts ${ }^{17}$ in year $\mathrm{t}-1,0$ otherwise. We rerun equation (5) using subsamples using observations with debt issuance $(\mathrm{DEBT}=1)$ and observations without debt issuance $($ DEBT $=0)$. As reported in Table 6 , we find that the coefficients on two measures of conditional conservatism, CSCORE_RANK and CONS_RANK, are larger for the subsample with debt issuance (columns [1] and [3]) than the subsample without debt issuance (columns [2] and [4]). We perform an F-test under the null hypothesis of no difference between the coefficients estimated in the two subsamples with debt issuance and without debt issuance. The evidence shows that coefficients are statistically different (e.g. p-values are 0.0252 and 0.0134 when the independent variable is CSCORE_RANK and CONS_RANK, respectively). The

\footnotetext{
${ }^{17}$ We use the threshold of 5 percent to make sure that the debt issuance is significant enough to affect conditional conservatism.
} 
evidence is consistent with our prediction that the relationship between conservatism and deviations from Benford's Law is more pronounced when firms have debt issuance.

[Insert Table 6 around here]

\subsection{Financial Distress}

Our next analysis uses subsamples of leveraged firms. Because conditional conservatism helps to provide debtholders with an early indication of the creditworthiness of borrowers (e.g., Zhang, 2008; Nikolaev, 2010), we further predict that leveraged firms adopt more conditional conservatism to comply with debt contract terms when they are facing financial distress. When leveraged firms report more conservative financial reports, deviations of first digits from Benford's Law increase. Therefore, we predict that the association between conditional conservatism and deviation from Benford's Law is more pronounced for leveraged firms which are in financial distress.

We test our analysis using subsamples of leveraged firms with and without financial distress. We create a dummy variable, denoted DISTRESS, that takes the value of 1 if leveraged firms have a Z-score greater than or equal to zero, and 0 if leveraged firms have a Z-score lower than zero; where leveraged firms are firms with the ratio of total debts to total assets greater than zero and Z-score is calculated following Taffler (1983). ${ }^{18}$ Table 7 reports our findings of running equation (5) using subsamples of observations based on DISTRESS. The result shows that the coefficients on CSCORE_RANK and CONS_RANK are larger in the subsample of leveraged firms with financial distress (columns [1] and [3]) than in the subsample without financial distress (columns [2] and [4]). We perform an F-test for the null hypothesis of no difference between the coefficients estimated in the two subsamples with financial distress and

\footnotetext{
${ }^{18}$ Our analysis excludes observations with zero financial leverage.
} 
without financial distress. The evidence shows that the coefficients are statistically different (e.g., p-values are 0.0610 and 0.0096 when the independent variable is CSCORE_RANK and CONS_RANK, respectively). The finding is consistent with our prediction.

[Insert Table 7 around here]

In general, this section provides evidence on possible channels for the relationship between conditional conservatism and deviations from Benford's Law. We find that the relationship is more pronounced for firms with debt issuance, and leveraged firms facing financial distress.

\section{Additional analyses}

Our last analyses provide evidence for the conformity to Benford's Law of the first digits of numbers reported in financial statements of UK listed companies. Similar to Amiram et al. (2015), who find that the first digits of financial statement items of US listed companies follow Benford's Law, we use data from the UK context and hypothesise that the first digits of financial statement items conform to Benford's Law at both the firm-specific and market levels.

To test the conformity to Benford's Law based on all digits from 0 and 9, the existing literature suggests two methods: the Kolmogorov-Smirnov (KS) test and the mean absolute deviation (MAD) test (Nigrini and Mittermaier, 1997; Amiram et al., 2015; Nigrini, 2015). ${ }^{19}$ We use the KS test for conformity at firm-specific level and MAD test at the market level.

At the firm-specific level, we rely on KS values as specified in equation (6). The KS is more relevant to test the conformity to Benford's Law at the firm-specific level when the number of digits analysed is small. The critical value, also known as Kolmogorov-Smirnov value, is used

\footnotetext{
${ }^{19}$ Previous studies have also documented that conformity to Benford's Law can be tested for each digit, i.e. to see whether distributions of the digits $0,1, \ldots$, and 9 follow Benford's Law. This method is applied in some research which examines particular digits, e.g. studies on rounding up behaviour only focus on small digits (0 and 1) and large digits (9) (Carslaw, 1988; Thomas, 1989; Niskanen and Keloharju, 2000; Caneghem, 2002, 2004). To test the conformity of each digit, prior research (Amiram et al., 2015; Nigrini, 2015) uses the chi-square $\left(\chi^{2}\right)$ test, which uses the z-statistic as the critical value.
} 
to test whether a data set conforms to Benford's Law at the $5 \%$ level of significance is $1.36 / \sqrt{\mathrm{P}}$, where $\mathrm{P}$ is the total number of first digits (Amiram et al., 2015). If the KS statistic of a company in a year is less than the test value, it is evidence suggesting the distribution of the first digits conforms to Benford's Law.

Panel A of Table 8 reports the findings for the conformity to Benford's Law at the firm-specific level. We observe that the percentage of firm-year observations following Benford's Law is $90.86 \%$, which is slightly higher than the conformity ratio of US companies for the period from 2001 to 2011, which is $85.63 \%$ (Amiram et al., 2015, page 1584). Also, in untabulated results, we find that the conformity rates level off around $91 \%$ for at least eight years, suggesting that financial statements of UK listed companies maintain high levels of conformity. The finding supports the notion that the first digits of financial statement items of UK listed companies follow Benford's Law at the firm-specific level.

[Insert Table 8 around here]

At the market level, we calculate one aggregate FSD score following equation (1) for the whole market using the pool of first digits of financial statements of all companies in the sample. Because the pool of all first digits is significant, the use of the FSD-score-based MAD overcomes the drawback of the KS statistic, which is sensitive to the total number of digits (P) (Amiram et al., 2015). While there is no critical value for the market-level test, we rely on the suggested MAD range values (Drake and Nigrini, 2000; Nigrini, 2012) to test the first-digit conformity to Benford's Law. ${ }^{20}$ If the FSD of the whole market is less than or equal to 0.012 , the distribution of the first digits conforms to Benford's Law.

\footnotetext{
${ }^{20}$ Drake and Nigrini (2000) and Nigrini (2012) suggest four levels of conformity of first digits: close conformity (MAD values range from 0.000 to 0.004 ), acceptable conformity (MAD values range from 0.004 to 0.008 ), marginally acceptable conformity (MAD values range from 0.008 to 0.012 ), and non-conformity (MAD values are greater than 0.012 ).
} 
Panel B of Table 8 reports the findings from the test of the conformity to Benford's Law at the market level. The findings show that the aggregate FSD for the entire market is 0.0010 , similar to that reported by Amiram et al. (2015) for companies listed in the US. ${ }^{21}$ The small aggregate FSD falls within the first predetermined range (from 0.000 to 0.004 ) of conformity suggested by previous studies (Drake and Nigrini, 2000; Nigrini, 2012). The results indicate that the firstdigit distributions of UK listed companies closely conform to Benford's Law. To have a closer look at the conformity level by each component of financial statements, we calculate three different FSD for income statements, balance sheets and cash flow statements. In untabulated results, we find that FSD for income statement items, balance sheet items and cash flow items are $0.0014,0.0009$ and 0.0011 , respectively. Those small figures also indicate that the first digits of separate components of financial statements closely conform to Benford's Law, with the deviations of income statements are larger than those of balance sheets and cash flows statements. The reason for a larger deviation for income statement items may be that managers are more likely to manipulate income statement items. The result is consistent with our expectations and similar to the findings of Amiram et al. (2015).

\section{Conclusions}

In this research, we apply Benford's Law to study the distributions of the first digits of financial statement items of UK listed companies. We hypothesise and find evidence that conditional conservatism is positively related to deviations of first digits from Benford's Law. The findings are robust for alternative measures of deviations and conditional conservatism. Also, we provide collaborative findings that the relationship between conditional conservatism and firstdigit deviations from Benford's Law is more pronounced for firms with debt issuance, and for leveraged firms facing financial distress. In addition, we document the conformity to Benford's

\footnotetext{
${ }^{21}$ In the US, Amiram et al. (2015) report that the aggregate FSD of listed companies in US from 2001 to 2011 is 0.0009.
} 
Law of the first digits on financial statements published by UK listed companies at both the firm-specific and market level.

This research makes significant contributions to the literature. First, we are the first to provide an alternative explanation for the deviations of the first digits of figures on financial statements from Benford's Law. Previous studies argue that the deviation of the digits of accounting numbers from Benford's Law is mainly caused by an introduction of frauds, errors or biases, such as earnings management (Caneghem, 2002, 2004; Amiram et al., 2015). Our findings suggest that conditional conservatism can be a source of first-digit deviations. Second, we provide evidence to confirm the previous findings reported by Amiram et al. (2015) that the first digits of financial statements of listed companies follow Benford's Law, by using data from a different context (UK data).

Our findings also have implications for practitioners such as auditors. Our results support the use of Benford's Law as an analytical procedure in an audit engagement because Benford's Law can flag material misstatements in accounting data. Our evidence show that deviations of first digits are positively related to both earnings management and conditional conservatism. The findings suggest that auditors should be aware of "false positive" for material misstatements when using Benford's Law as a risk assessment procedure. While both conditional conservatism and earnings management are related to deviations from Benford's Law, conservatism-related biases could indicate less audit risks and thus be desirable for auditors. Heavy dependence on Benford's Law may lead to excessive substantive audit procedures due to false-positive results from the risk assessment, which reduces the efficiency of the audit engagement (e.g., excessive costs and potential losses for auditing firms). Also, the auditors need to carefully consider some specific circumstances, e.g. when firms have debt issuance or are facing financial distress, because managers may have more incentivies to 
exercise discretion over the timely recognition of bad news, e.g. impairment losses, evidenced by higher deviations of first digits from Benford's Law.

We acknowledge a limitation of our research. Although we provide robust findings suggesting that conditional conservatism is a source of first-digit deviations from Benford's Law, our research provides limited evidence for a causal relationship, e.g., reverse causality could exist. While it is more reasonable to expect that conditional conservatism affects first-digit deviations from Benford's Law, not the other way around, we recommend that readers should interpret the findings with caution. 


\section{References}

Ahmed, A. S., Billings, B. K., Morton, R. M., \& Stanford-Harris, M. (2002). The Role of Accounting Conservatism in Mitigating Bondholder-Shareholder Conflicts over Dividend Policy and in Reducing Debt Costs. Accounting Review, 77(4), 867-890.

Al-Shaer, H., \& Harakeh, M. (2020). Gender Differences in Executive Compensation on British Corporate Boards: the Role of Conditional Conservatism. The International Journal of Accounting, 55(01), 2050002.

Amiram, D., Bozanic, Z., \& Rouen, E. (2015). Financial Statement Errors: Evidence from the Distributional Properties of Financial Statement Numbers. Review of Accounting Studies, 20(4), 1540-1593.

Ball, R., Kothari, S. P., \& Nikolaev, V. V. (2013a). On Estimating Conditional Conservatism. Accounting Review, 88(3), 755-787.

Ball, R., \& Shivakumar, L. (2005). Earnings Quality in UK Private Firms: Comparative Loss Recognition Timeliness. Journal of Accounting and Economics, 39(1), 83-128.

Ball, R. A. Y., Kothari, S. P., \& Nikolaev, V. V. (2013b). Econometrics of the Basu Asymmetric Timeliness Coefficient and Accounting Conservatism. Journal of Accounting Research, 51(5), 1071-1097.

Banker, R. D., Basu, S., Byzalov, D., \& Chen, J. Y. S. (2012). Direction of Sales Change and Asymmetric Timeliness of Earnings. Working paper. Temple University. Retrieved from

http://www.fox.temple.edu/cms/wpcontent/uploads/2012/09/consSDpaper120910inclNames.pdf

Basu, S. (1997). The Conservatism Principle and the Asymmetric Timeliness of Earnings. Journal of Accounting and Economics, 24(1), 3-37.

Basu, S., \& Liang, Y. (2019). Director-Liability-Reduction Laws and Conditional Conservatism. Journal of Accounting Research, 57(4), 889-917.

Beaver, W. H., \& Ryan, S. G. (2005). Conditional and Unconditional Conservatism:Concepts and Modeling. Review of Accounting Studies, 10(2/3), 269-309.

Burke, Q. L., Chen, P.-C., \& Lobo, G. J. (2020). Is Corporate Social Responsibility Performance Related to Conditional Accounting Conservatism? Accounting Horizons, 34(2), 19-40.

Caneghem, T. V. (2002). Earnings Management Induced By Cognitive Reference Points. The British Accounting Review, 34(2), 167-178.

Caneghem, T. V. (2004). The Impact of Audit Quality on Earnings Rounding-up Behaviour: some UK Evidence. European Accounting Review, 13(4), 771-786.

Carslaw, C. A. (1988). Anomalies in Income Numbers: Evidence of Goal Oriented Behavior. Accounting Review, 63(2), 321-327.

Caskey, J., \& Laux, V. (2017). Corporate Governance, Accounting Conservatism, and Manipulation. Management Science, 63(2), 424-437.

Da Silva, C. G., \& Carreira, P. M. R. (2013). Selecting Audit Samples Using Benford's Law. Auditing: A Journal of Practice \& Theory, 32(2), 53-65.

Dai, L., \& Ngo, P. (2020). Political Uncertainty and Accounting Conservatism. European Accounting Review, 1-32.

Dechow, P. M., Ge, W., Larson, C. R., \& Sloan, R. G. (2011). Predicting Material Accounting Misstatements. Contemporary Accounting Research, 28(1), 17-82.

Dechow, P. M., Sloan, R. G., \& Sweeney, A. P. (1995). Detecting Earnings Management. Accounting Review, 70(2), 193-225.

Dietrich, J. R., Muller, K. A., \& Riedl, E. J. (2007). Asymmetric Timeliness Tests of Accounting Conservatism. Review of Accounting Studies, 12(1), 95-124. 
Drake, P. D., \& Nigrini, M. J. (2000). Computer Assisted Analytical Procedures Using Benford's Law. Journal of Accounting Education, 18(2), 127-146.

Durtschi, C., Hillison, W., \& Pacini, C. (2004). The Effective Use of Benford's Law to Assist in Detecting Fraud in Accounting Data. Journal of Forensic Accounting, 5(1), 17-34.

Financial Accounting Standards Board. (1980). Statement of Financial Accounting Concepts No. 2, Qualitative Characteristics of Accounting Information. In. Norwalk, CT: FASB.

Francis, B., Hasan, I., Park, J. C., \& Wu, Q. (2015). Gender Differences in Financial Reporting Decision Making: Evidence from Accounting Conservatism. Contemporary Accounting Research, 32(3), 1285-1318.

Francis, B., Hasan, I., \& Wu, Q. (2013). The Benefits of Conservative Accounting to Shareholders: Evidence from the Financial Crisis. Accounting Horizons, 27(2), 319346.

García Lara, J. M., García Osma, B., \& Penalva, F. (2011). Conditional Conservatism and Cost of Capital. Review of Accounting Studies, 16(2), 247-271.

García Lara, J. M., García Osma, B., \& Penalva, F. (2016). Accounting Conservatism and Firm Investment Efficiency. Journal of Accounting and Economics, 61(1), 221-238.

García Lara, J. M., García Osma, B., \& Penalva, F. (2020). Conditional conservatism and the limits to earnings management. Journal of Accounting and Public Policy, 39(4).

Givoly, D., Hayn, C. K., \& Natarajan, A. (2007). Measuring Reporting Conservatism. Accounting Review, 82(1), 65-106.

Goh, B. W., Lim, C. Y., Lobo, G. J., \& Tong, Y. H. (2017). Conditional Conservatism and Debt versus Equity Financing. Contemporary Accounting Research, 34(1), 216-251.

Goh, L., \& Gupta, A. (2016). Remuneration of Non-executive Directors: Evidence from the UK. British Accounting Review, 48(3), 379-399.

Heflin, F., Hsu, C., \& Jin, Q. (2015). Accounting Conservatism and Street Earnings. Review of Accounting Studies, 20(2), 674-709.

Ho, S. S. M., Li, A. Y., Tam, K., \& Zhang, F. (2015). CEO Gender, Ethical Leadership, and Accounting Conservatism. Journal of Business Ethics, 127(2), 351-370.

Hsu, A., O'Hanlon, J., \& Peasnell, K. (2012). The Basu Measure as an Indicator of Conditional Conservatism: Evidence from UK Earnings Components. European Accounting Review, 21(1), 87-113.

International Accounting Standards Board (IASB). (2018). Conceptual Framework for Financial Reporting. In. United Kingdom: IFRS Foundation.

International Accounting Standards Committee. (1989). Framework for the Preparation and Presentation of Financial Statements (the Framework).

Jones, J. J. (1991). Earnings Management During Import Relief Investigations. Journal of Accounting Research, 29(2), 193-228.

Khan, M., \& Watts, R. L. (2009). Estimation and Empirical Properties of a Firm-year Measure of Accounting Conservatism. Journal of Accounting and Economics, 48(2-3), 132-150.

Kim, J.-B., \& Zhang, L. (2016). Accounting Conservatism and Stock Price Crash Risk: Firmlevel Evidence. Contemporary Accounting Research, 33(1), 412-441.

Kravet, T. D. (2014). Accounting Conservatism and Managerial Risk-Taking: Corporate Acquisitions. Journal of Accounting and Economics, 57(2-3), 218-240.

Krishnan, G. V. (2003). Does Big 6 Auditor Industry Expertise Constrain Earnings Management? Accounting Horizons, 17, 1.

Kwon, Y. K. (2005). Accounting Conservatism and Managerial Incentives. Management Science, 51(11), 1626-1632.

Kwon, Y. K., Niwman, D. P., \& Suh, T. S. (2001). The Demand for Accounting Conservatism for Management Control. Review of Accounting Studies, 6(1), 29-51. 
LaFond, R., \& Watts, R. L. (2008). The Information Role of Conservatism. Accounting Review, 83(2), 447-478.

Li, J. (2013). Accounting Conservatism and Debt Contracts: Efficient Liquidation and Covenant Renegotiation. Contemporary Accounting Research, 30(3), 1082-1098.

Lin, F., Wu, C.-M., Fang, T.-Y., \& Wun, J.-C. (2014). The Relations among Accounting Conservatism, Institutional Investors and Earnings Manipulation. Economic Modelling, 37, 164-174.

Lobo, G. J., Robin, A., \& Wu, K. (2019). Share Repurchases and Accounting Conservatism. Review of Quantitative Finance and Accounting.

Mora, A., \& Walker, M. (2015). The Implications of Research on Accounting Conservatism for Accounting Standard Setting. Accounting and Business Research, 45(5), 620-650.

Moy, M., Heaney, R., Tarca, A., \& van Zyl, W. (2020). Conditional accounting conservatism: Exploring the impact of changes in institutional frameworks in four countries. Journal of Contemporary Accounting \& Economics, 16(3).

Mukherjee, S. (2017). Can Benford's Law explain CEO pay? Corporate Governance: An International Review, n/a-n/a.

Muttakin, M. B., Khan, A., \& Tanewski, G. (2019). CFO Tenure, CFO Board Membership and Accounting Conservatism. Journal of Contemporary Accounting \& Economics, 15(3).

Nguyen, T. T., Duong, C. M., Nguyen, N. T. M., \& Bui, H. Q. (2020). Accounting Conservatism and Banking Expertise on Board of Directors. Review of Quantitative Finance and Accounting, 55, 501-539.

Nigrini, M. J. (1994). Using Digital Frequencies to Detect Fraud. The White Paper, 8(2), 3-6.

Nigrini, M. J. (1996). A Taxpayer Compliance Application of Benford's Law. Journal of the American Taxation Association, 18(1), 72-91.

Nigrini, M. J. (2012). Benford's Law: Applications for Forensic Accounting, Auditing, and Fraud Detection (Vol. 586): John Wiley \& Sons.

Nigrini, M. J. (2015). Persistent Patterns in Stock Returns, Stock Volumes, and Accounting Data in the U.S. Capital Markets. Journal of Accounting, Auditing and Finance, 30(4), 541-557.

Nigrini, M. J., \& Mittermaier, L. J. (1997). The Use of Benford's Law as an Aid in Analytical Procedures. AUDITING: A Journal of Practice \& Theory, 16(2), 52-67.

Nikolaev, V. V. (2010). Debt Covenants and Accounting Conservatism. Journal of Accounting Research, 48(1), 51-89.

Niskanen, J., \& Keloharju, M. (2000). Earnings Cosmetics in a Tax-Driven Accounting Environment: Evidence from Finnish Public Firms. European Accounting Review, 9(3), 443-452.

Pae, J., Thornton, D. B., \& Welker, M. (2005). The Link between Earnings Conservatism and the Price-to-Book Ratio. Contemporary Accounting Research, 22(3), 693-717.

Ramanna, K., \& Watts, R. L. (2012). Evidence on the use of unverifiable estimates in required goodwill impairment. Review of Accounting Studies, 17(4), 749-780.

Richardson, S. A., Sloan, R. G., Soliman, M. T., \& Tuna, İ. (2005). Accrual Reliability, Earnings Persistence and Stock Prices. Journal of Accounting and Economics, 39(3), 437-485.

Roychowdhury, S., \& Watts, R. L. (2007). Asymmetric Timeliness of Earnings, Market-toBook and Conservatism in Financial Reporting. Journal of Accounting and Economics, 44(1-2), 2-31.

Suijs, J. (2008). On the Value Relevance of Asymmetric Financial Reporting Policies. Journal of Accounting Research.

Taffler, R. J. (1983). The Assessment of Company Solvency and Performance Using a Statistical Model. Accounting and Business Research, 13(52), 295-308. 
Thomas, J. K. (1989). Unusual Patterns in Reported Earnings. Accounting Review, 773-787.

Watts, R. L. (2003a). Conservatism in Accounting Part I: Explanations and Implications. Accounting Horizons, 17(3), 207-221.

Watts, R. L. (2003b). Conservatism in Accounting Part II: Evidence and Research Opportunities. Accounting Horizons, 17(4), 287-301.

Watts, R. L., \& Zimmerman, J. L. (1990). Positive Accounting Theory: A Ten Year Perspective. The Accounting Review, 65(1), 131-156.

Zhang, J. (2008). The Contracting Benefits of Accounting Conservatism to Lenders and Borrowers. Journal of Accounting and Economics, 45(1), 27-54. 


\section{APPENDIX: VARIABLE DEFINITIONS}

\begin{tabular}{|c|c|}
\hline $\mathrm{FSD}_{\text {it }}$ & $\begin{array}{l}\qquad \text { FSD }_{\mathrm{it}}=\frac{\sum_{\mathrm{d}=1}^{9} \mid \mathrm{OBSERVED}_{\mathrm{dit}}-\text { EXPECTED }_{\mathrm{d}} \mid}{9} \\
\text { Where: } \mathrm{FSD}_{\mathrm{it}} \text { is the mean absolute deviation of the first digits of financial statement items from Benford's Law of firm } \mathrm{i} \\
\text { in year } \mathrm{t} ; \mathrm{OBSERVED}_{\mathrm{d}, \mathrm{i}, \mathrm{t}} \text { is the actual probability of the first digit } \mathrm{d} \text { of firm } \mathrm{i} \text { in year } \mathrm{t} \text {; EXPECTED } \\
\text { probability of the first digit d following Benford's Law; and } \mathrm{d}=1,2, \ldots, 9 \text {. }\end{array}$ \\
\hline $\mathrm{KS}_{\text {it }}$ & $\begin{array}{l}\mathrm{KS}_{\mathrm{it}}=\max \left\{\left|\mathrm{OD}_{1 \mathrm{it}}-\mathrm{ED}_{1}\right|,\left|\left(\mathrm{OD}_{1 \mathrm{it}}+\mathrm{OD}_{2 \mathrm{it}}\right)-\left(\mathrm{ED}_{1}+\mathrm{ED}_{2}\right)\right|, \ldots, \mid\left(\mathrm{OD}_{1 \mathrm{it}}+\mathrm{OD}_{2 \mathrm{it}}+\cdots+\mathrm{OD}_{9 \mathrm{it}}\right)-\left(\mathrm{ED}_{1}+\mathrm{ED}_{2}+\cdots\right.\right. \\
\left.\left.\quad+\mathrm{ED}_{9}\right) \mid\right\} \\
\text { Where } \mathrm{KS}_{\text {it }} \text { is the maximum cumulative absolute deviation of the first digits of figures reported in financial statements } \\
\text { from what are expected by Benford's Law of firm } \mathrm{i} \text { in year } \mathrm{t} ; \mathrm{OD}_{\text {dit }} \text { is the cumulative observed probability of the first } \\
\text { digit } \mathrm{d}(\mathrm{d}=1,2, \ldots, 9) \text { of firm i in year } \mathrm{t} ; \mathrm{ED}_{\mathrm{d}} \text { is the expected probability of the first digit } \mathrm{d}(\mathrm{d}=1,2, \ldots, 9) \text { as defined } \\
\text { by Benford's Law. }\end{array}$ \\
\hline CSCORE_RANK $_{\text {it }}$ & $\begin{array}{l}\text { Conditional conservatism, which is the annual fractional rank of CSCORE it (incremental timeliness of bad news over } \\
\text { good news) (Basu, 1997; Khan and Watts, 2009; García Lara et al., 2016). }\end{array}$ \\
\hline CONS_RANK & $\begin{array}{l}\text { Total conservatism or total timeliness of bad news, which is the annual fractional rank of CONS } \\
\text { sum of } \text { CSCORE } E_{\text {it }} \text { (incremental timeliness of bad news over good news) and GSCORE } \text { it }_{\text {it }} \text { is the theliness of good news) } \\
\text { (Basu, 1997; Khan and Watts, 2009; García Lara et al., 2016). }\end{array}$ \\
\hline $\mathrm{DAC}_{\mathrm{it}}$ & 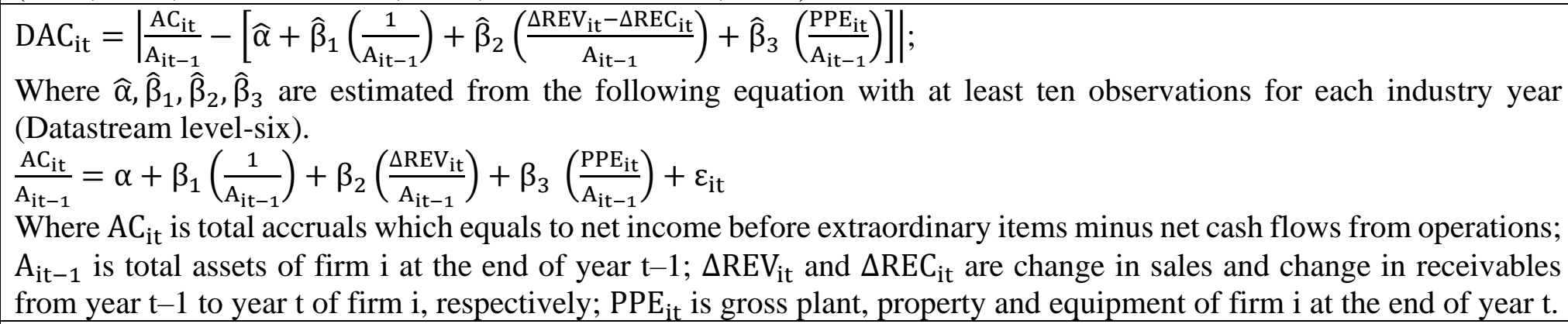 \\
\hline FRAUD $_{\text {it }}$ & $\begin{array}{l}\text { equal to one if FSCORE is greater than one, zero otherwise; where FSCORE is calculated as follows: } \\
\text { Predicted Value } \\
\qquad \begin{aligned}=-7.893+0.790 * \text { ACC_RSST }+2.581 * \Delta \mathrm{REC}+1.191 * \Delta \mathrm{INV}+1.979 * \text { SOFTASSET } \\
+0.171 * \Delta \mathrm{CASH}-0.932 * \Delta \mathrm{ROA}+1.029 * \mathrm{SEO}\end{aligned}\end{array}$ \\
\hline
\end{tabular}




\begin{tabular}{|c|c|}
\hline & 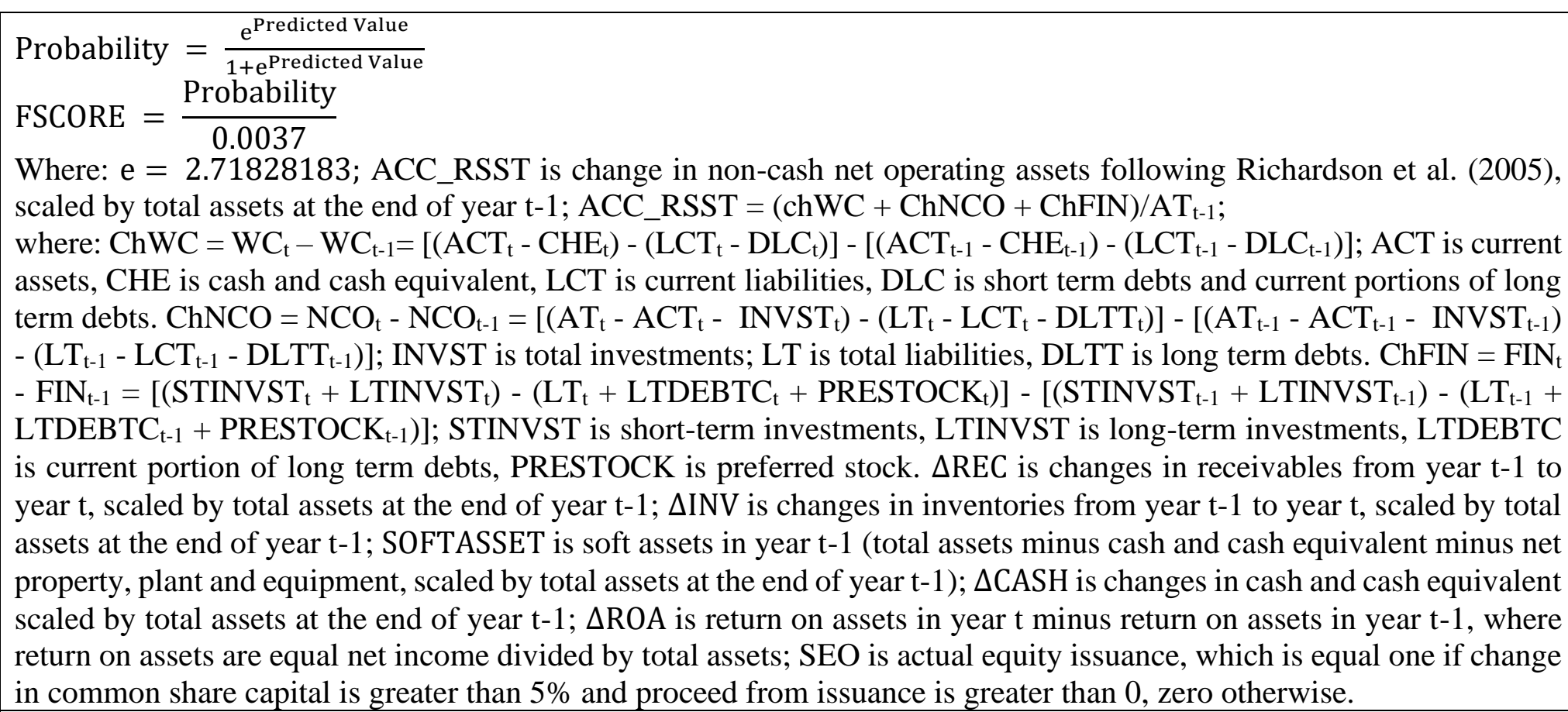 \\
\hline LOSS $_{\text {it }}$ & equal to one if net incomes before extraordinary items in year t-2 and year t-1 are both negative, zero otherwise. \\
\hline EARN $_{\text {it }}$ & Net income before extraordinary items in year $\mathrm{t}$, scaled by the market value of equity at the end of year $\mathrm{t}-1$ \\
\hline RET $_{\text {it }}$ & Buy-and-hold stock returns for fiscal year t. \\
\hline $\mathrm{D}_{\mathrm{it}}$ & A dummy variable which is either equal to 1 if $\mathrm{RET}_{\mathrm{it}}<0$, otherwise 0 . \\
\hline SIZE $_{\mathrm{it}-1}$ & the natural $\log$ of the market value of equity at the end of year $\mathrm{t}-1$. \\
\hline MTB $_{\text {it-1 }}$ & the market-to-book ratio at the end of year $\mathrm{t}-1$. \\
\hline $\mathrm{LEV}_{\mathrm{it}-1}$ & $\begin{array}{l}\text { the sum of long-term and short-term debts at the end of year } t-1 \text {, scaled by the market value of equity at the end of year } \\
\mathrm{t}-1 \text {. }\end{array}$ \\
\hline $\mathrm{DEBT}_{\text {it }}$ & $\begin{array}{l}\text { Debt issuance, a dummy variable that takes a value of } 1 \text { if an increase in total debts from year } t-1 \text { to year } t \text { is greater } \\
\text { than or equal to } 5 \text { percent of total debts in year } t-1 \text {, otherwise } 0 .\end{array}$ \\
\hline
\end{tabular}




\begin{tabular}{|c|c|}
\hline DISTRESS $_{\text {it }}$ & $\begin{array}{l}\text { Financial distress, which is equal to } 1 \text { if a firm has a negative Z-score following Taffler (1983), and otherwise } 0 . \text { Z- } \\
\text { score is calculated as follows: Z-score }=3.2+12.18 * \frac{\text { Profit before tax }}{\text { current liabilities }}+2.5 * \frac{\text { Current assets }}{\text { Total liabilities }}-10.68 * \frac{\text { Current liabilities }}{\text { Total assets }}+ \\
0.029 * \frac{\text { (Quick assets-Current liabilities) }}{\text { (Sales-Pretax income-Depreciation) } / 365}\end{array}$ \\
\hline
\end{tabular}




\section{Table 2: Descriptive statistics}

This table reports the number of observations $(\mathrm{N})$, mean (MEAN), standard deviation (STD), median (MEDIAN), 25 ${ }^{\text {th }}(\mathrm{P} 25)$, and $75^{\text {th }}(\mathrm{P} 75)$ percentiles of firm characteristics and selected variables. Definitions of variables are in the Appendix.

\begin{tabular}{|c|c|c|c|c|c|c|}
\hline Variables & $\mathbf{N}$ & MEAN & STD & MEDIAN & $\mathbf{P 2 5}$ & P75 \\
\hline $\mathrm{AT}_{\text {it }}$ & 3,635 & $1,020,420$ & $3,612,198$ & 120,127 & 36,874 & 530,592 \\
\hline Sale $_{i t}$ & 3,635 & 818,674 & $2,559,972$ & 121,071 & 26,067 & 549,600 \\
\hline Net income before extraordinary & 3,635 & & & & & \\
\hline items $_{\text {it }}$ & & 71,504 & 403,825 & 4,677 & 491 & 28,200 \\
\hline Debt to assets ratio it & 3,635 & 0.315 & 0.999 & 0.131 & 0.007 & 0.355 \\
\hline Market to book ratio it & 3,635 & 4.039 & 20.544 & 2.084 & 1.251 & 3.566 \\
\hline $\mathrm{FSD}_{\mathrm{it}}$ & 3,635 & 0.032 & 0.010 & 0.031 & 0.025 & 0.037 \\
\hline $\mathrm{KS}_{\mathrm{it}}$ & 3,635 & 0.089 & 0.039 & 0.082 & 0.061 & 0.111 \\
\hline CSCORE_RANK $_{\text {it }}$ & 3,635 & 0.502 & 0.281 & 0.501 & 0.263 & 0.744 \\
\hline $\mathrm{DAC}_{\mathrm{it}}$ & 3,635 & 0.080 & 0.128 & 0.049 & 0.023 & 0.095 \\
\hline $\mathrm{LOSS}_{\mathrm{it}}$ & 3,635 & 0.153 & 0.360 & 0.000 & 0.000 & 0.000 \\
\hline FRAUD $_{\text {it }}$ & 3,635 & 0.102 & 0.303 & 0.000 & 0.000 & 0.000 \\
\hline
\end{tabular}




\section{Table 3: Pearson Correlations}

This table reports the Pearson correlation coefficients between selected variables. VIF shows the variance inflation factor. *, **, *** are significance at $10 \%, 5 \%$ and $1 \%$, respectively. Definitions of variables are in the Appendix.

\begin{tabular}{|c|c|c|c|c|c|c|c|}
\hline & FSD $_{\text {it }}$ & $\mathbf{K S}_{\mathbf{i t}}$ & CSCORE_RANK & DAC $_{\text {it }}$ & $\mathbf{L O S S}_{\text {it }}$ & FRAUDit $_{\text {it }}$ & VIF \\
\hline $\mathrm{FSD}_{\text {it }}$ & 1.00 & & & & & & \\
\hline $\mathrm{KS}_{\mathrm{it}}$ & $0.73 * * *$ & 1.00 & & & & & \\
\hline 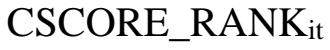 & $0.15 * * *$ & $0.11 * * *$ & 1.00 & & & & 1.14 \\
\hline $\mathrm{DAC}_{\mathrm{it}}$ & $0.13 * * *$ & $0.09 * * *$ & $0.08 * * *$ & 1.00 & & & 1.11 \\
\hline $\mathrm{LOSS}_{\mathrm{it}}$ & $0.24 * * *$ & $0.20 * * *$ & $0.15 * * *$ & $0.19 * * *$ & 1.00 & & 1.26 \\
\hline FRAUD $_{\text {it }}$ & $0.05 * * *$ & $0.03 *$ & $0.09 * * *$ & $0.17 * * *$ & $0.11 * * *$ & 1.00 & 1.22 \\
\hline
\end{tabular}




\section{Table 4: Main regression results}

The table reports the OLS regression results for the relationship between the deviation of first digits of numbers reported in financial statements and conditional conservatism. We run the following regression:

$\mathrm{FSD}_{\mathrm{it}}=\alpha+\beta_{1} *$ CSCORE_RANK ${ }_{\mathrm{it}}+\beta_{2} * \mathrm{DAC}_{\mathrm{it}}+\beta_{3} * \mathrm{LOSS}_{\mathrm{it}}+\beta_{4} * \mathrm{FRAUD}_{\mathrm{it}}+\mathrm{FE}+\varepsilon_{\mathrm{it}}(5)$

In equation (5), FSD stands for deviations from Benford's Law (Amiram et al., 2015) of firm i in year t. CSCORE_RANK is the firm-year measure of conditional conservatism (Basu, 1997; Khan and Watts, 2009; García Lara et al., 2016). DAC is discretionary accruals, which are estimated from the Jones-modified model (Jones, 1991; Dechow et al., 1995). LOSS is losses in previous years, which is equal to 1 if net incomes before extraordinary items in years $\mathrm{t}-2$ and $\mathrm{t}-1$ are both negative, 0 otherwise. FRAUD is based on the FSCORE following Dechow et al. (2011) (Model 1, Table 7) and is equal to 1 if FSCORE is greater than 1, otherwise 0. FE stands for year fixed effects (columns [1], [2], and [4]) and industry fixed effects (columns [1],[3], and [4]). All coefficients are multiplied by 100 for easy reading. Definitions of variables are in the Appendix. *, **, $* * *$ are significance at $10 \%, 5 \%$ and $1 \%$, respectively.

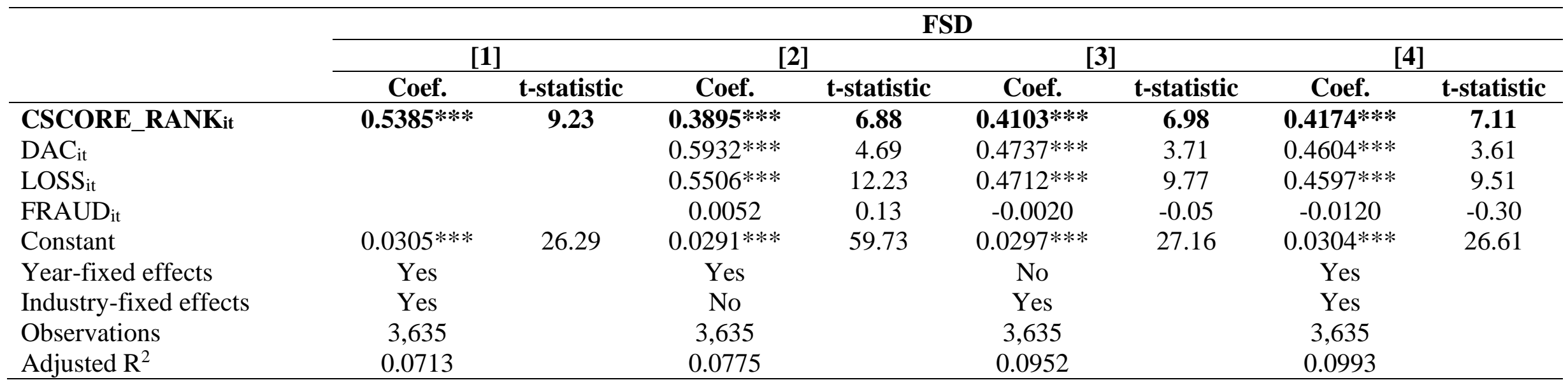




\section{Table 5: Alternative measures}

The table reports the OLS regression results for the relationship between the deviation of first digits of numbers reported in financial statements and conditional conservatism, using alternative measures. FSD stands for deviations from Benford's Law (Amiram et al., 2015) of firm $\mathrm{i}$ in year t. CSCORE_RANK is the firm-year measure of conditional conservatism (Basu, 1997; Khan and Watts, 2009; García Lara et al., 2016). DAC is discretionary accruals, which are estimated from the Jones-modified model (Jones, 1991; Dechow et al., 1995). LOSS is losses in previous years, which is equal to 1 if net incomes before extraordinary items in years $\mathrm{t}-2$ and $\mathrm{t}-1$ are both negative, 0 otherwise. FRAUD is based on the FSCORE following Dechow et al. (2011) (Model 1, Table 7) and is equal to 1 if FSCORE is greater than 1, otherwise 0. In Panel A, we rerun equation (5) by substituting FSD for KS, which is the maximum cumulative absolute deviation of the first digits of figures reported in financial statements from what are expected by Benford's Law of firm $i$ in year $t$ (Amiram et al., 2015). In Panel B, we rerun equation (5) by substituting CSCORE_RANK for CONS_RANK, which is the measure of total conditional conservatism (Basu, 1997; Khan and Watts, 2009; García Lara et al., 2016). In all regressions, we control for firm-fixed effects and industry-fixed effects. All coefficients are multiplied by 100 for easy reading. Definitions of variables are in the Appendix. $* * *, * * *$ are significance at $10 \%, 5 \%$ and $1 \%$, respectively.

Panel A: Alternative measure of deviation from Benford's Law

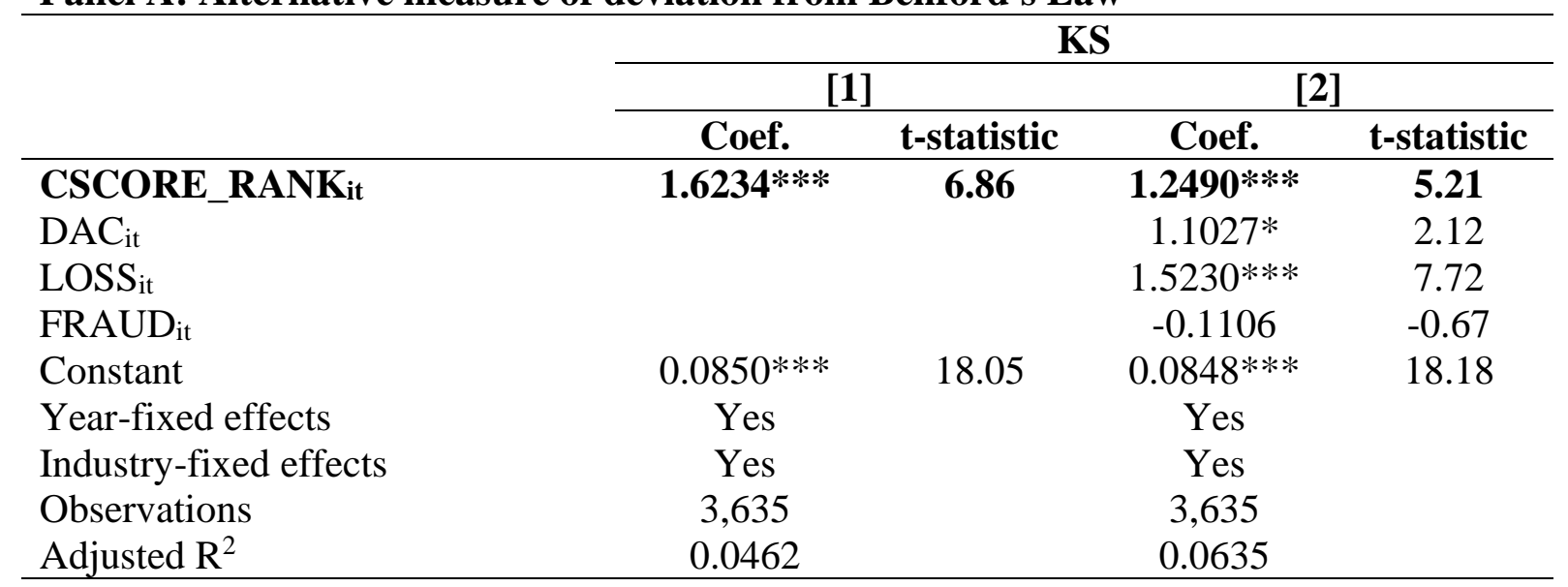

Panel B: Alternative measure of conditional conservatism

\begin{tabular}{lcccc}
\hline & \multicolumn{4}{c}{ FSD } \\
\cline { 2 - 5 } & \multicolumn{3}{c}{$[\mathbf{1 1}$} & \multicolumn{3}{c}{ [2] } \\
\cline { 2 - 5 } & Coef. & t-statistic & Coef. & t-statistic \\
\hline CONS_RANK & $\mathbf{0 . 5 4 1 3 * * *}$ & $\mathbf{9 . 3 1}$ & $\mathbf{0 . 4 1 8 0 * * *}$ & $\mathbf{7 . 1 4}$ \\
DAC $_{\text {it }}$ & & & $0.4628^{* * *}$ & 3.63 \\
LOSS $_{\text {it }}$ & & & $0.4569^{* * *}$ & 9.44 \\
FRAUD & & & -0.0061 & -0.15 \\
Constant & & & $0.0304 * * *$ & 26.57 \\
Year-fixed effects & $0.0305^{* * *}$ & 26.25 & Yes & \\
Industry-fixed effects & Yes & & Yes & \\
Observations & Yes & & 3,635 & \\
Adjusted R & 3,635 & & 0.0994 & \\
\hline
\end{tabular}




\section{Table 6: Debt Issuance}

The table reports the OLS regression results for the relationship between the deviation of first digits of numbers reported in financial statements and conditional conservatism, using subsamples with debt issuance and without debt issuance. We rerun equation (5) and report the findings for two alternative measures of conservatism, namely CSCORE_RANK (columns [1]-[2]) and CONS_RANK (columns [3]-[4]). FSD stands for deviations from Benford's Law (Amiram et al., 2015) of firm i in year t. CSCORE_RANK is the firm-year measure of conditional conservatism while CONS_RANK is the measure of total conditional conservatism (Basu, 1997; Khan and Watts, 2009; García Lara et al., 2016). DAC is discretionary accruals, which are estimated from the Jones-modified model (Jones, 1991; Dechow et al., 1995). LOSS is losses in previous years, which is equal to 1 if net incomes before extraordinary items in years $t-2$ and $t-1$ are both negative, 0 otherwise. FRAUD is based on the FSCORE following Dechow et al. (2011) (Model 1, Table 7) and is equal to 1 if FSCORE is greater than 1, otherwise 0. We report the findings for subsamples of firms with debt issuance (columns [1] and [3]) and without debt issuance (columns [2] and [4]). DEBT stands for debt issuance, which is a dummy variable that takes a value of 1 if an increase in total debts from year t- 1 to year $t$ is greater than or equal to 5 percent of total debts in year $\mathrm{t}-1$, otherwise 0 . In all regressions, we control for firm-fixed effects and industry-fixed effects. All coefficients are multiplied by 100 for easy reading. Definitions of variables are in the Appendix. *,**,*** are significance at $10 \%, 5 \%$ and $1 \%$, respectively.

\begin{tabular}{|c|c|c|c|c|c|c|c|c|}
\hline & \multirow{2}{*}{\multicolumn{2}{|c|}{$\begin{array}{c}\text { DEBT }=1 \\
{[1]}\end{array}$}} & \multirow{2}{*}{\multicolumn{2}{|c|}{$\begin{array}{c}\text { DEBT }=0 \\
{[2]}\end{array}$}} & \multirow{2}{*}{\multicolumn{2}{|c|}{$\begin{array}{c}\text { DEBT }=1 \\
{[3]}\end{array}$}} & \multirow{2}{*}{\multicolumn{2}{|c|}{$\begin{array}{c}\text { DEBT }=0 \\
{[4]}\end{array}$}} \\
\hline & & & & & & & & \\
\hline & Coef. & t-statistic & Coef. & t-statistic & Coef. & t-statistic & Coef. & t-statistic \\
\hline CSCORE_RANK $_{\text {it }}$ & $0.4660 * * *$ & 3.99 & $0.3980 * * * *$ & 5.76 & & & & \\
\hline CONS_RĀNKit & & & & & $0.4425 * * *$ & 3.77 & $0.4047 * * *$ & 5.91 \\
\hline $\mathrm{DAC}_{\mathrm{it}}{ }^{-}$ & $0.5882 * *$ & 2.65 & $0.4047 *$ & 2.56 & $0.5980^{* *}$ & 2.69 & $0.4077 * *$ & 2.58 \\
\hline $\mathrm{LOSS}_{\mathrm{it}}$ & $0.3207 * *$ & 3.08 & $0.4733 * * *$ & 8.52 & $0.3275^{* *}$ & 3.15 & $0.4675 * * *$ & 8.40 \\
\hline FRAUD $_{\text {it }}$ & 0.0052 & 0.08 & 0.0272 & 0.51 & 0.0154 & 0.23 & 0.0329 & 0.62 \\
\hline Constant & $0.0287 * * *$ & 11.12 & $0.0309 * * *$ & 24.01 & $0.0288 * * *$ & 11.15 & $0.0308 * * *$ & 23.95 \\
\hline Year-fixed effects & Yes & & Yes & & Yes & & Yes & \\
\hline Industry-fixed effects & Yes & & Yes & & Yes & & Yes & \\
\hline Observations & 878 & & 2,757 & & 878 & & 2,757 & \\
\hline Adjusted $\mathrm{R}^{2}$ & 0.0747 & & 0.1011 & & 0.0728 & & 0.1017 & \\
\hline \multicolumn{9}{|l|}{ F-test for difference in } \\
\hline coefficient $\beta_{1}$ between & \multicolumn{4}{|c|}{ [1] vs [2] } & \multicolumn{4}{|c|}{ [3] vs [4] } \\
\hline F-statistic & \multicolumn{4}{|c|}{5.01} & \multicolumn{4}{|c|}{6.12} \\
\hline P-value & \multicolumn{4}{|c|}{0.0252} & \multicolumn{4}{|c|}{0.0134} \\
\hline
\end{tabular}




\section{Table 7: Financial Distress}

The table reports the OLS regression results for the relationship between the deviation of first digits of numbers reported in financial statements and conditional conservatism for subsamples of leveraged firms with financial distress (columns [1] and [3]) and leveraged firms without financial distress (columns [2] and [4]). We rerun equation (5) and report the findings for two alternative measures of conservatism, namely CSCORE_RANK and CONS_RANK. FSD stands for deviations from Benford's Law (Amiram et al., 2015) of firm i in year t. CSCORE_RANK is the firm-year measure of conditional conservatism, while CONS_RANK is the measure of total conservatism (Basu, 1997; Khan and Watts, 2009; García Lara et al., 2016). DAC is discretionary accruals, which are estimated from the Jones-modified model (Jones, 1991; Dechow et al., 1995). LOSS is losses in previous years, which is equal to 1 if net incomes before extraordinary items in years $t-2$ and $t-1$ are both negative, 0 otherwise. FRAUD is based on the FSCORE following Dechow et al. (2011) (Model 1, Table 7) and is equal to 1 if FSCORE is greater than 1, otherwise 0. DISTRESS is financial distress, which is equal to 1 if a firm has a negative Z-score following Taffler (1983), and otherwise 0. In all regressions, we control for firm-fixed effects and industry-fixed effects. All coefficients are multiplied by 100 for easy reading. Definitions of variables are in the Appendix. *,**,*** are significance at $10 \%, 5 \%$ and $1 \%$, respectively.

\begin{tabular}{|c|c|c|c|c|c|c|c|c|}
\hline & \multirow{2}{*}{\multicolumn{2}{|c|}{$\begin{array}{c}\text { DISTRESS = 1 } \\
{[1]}\end{array}$}} & \multirow{2}{*}{\multicolumn{2}{|c|}{$\begin{array}{c}\text { DISTRESS }=0 \\
{[2]}\end{array}$}} & \multirow{2}{*}{\multicolumn{2}{|c|}{$\begin{array}{c}\text { DISTRESS }=\mathbf{1} \\
{[3]}\end{array}$}} & \multirow{2}{*}{\multicolumn{2}{|c|}{$\begin{array}{c}\text { DISTRESS }=0 \\
{[4]}\end{array}$}} \\
\hline & & & & & & & & \\
\hline & Coef. & t-statistic & Coef. & t-statistic & Coef. & t-statistic & Coef. & t-statistic \\
\hline CSCORE_RANK & $0.6413 * * *$ & 4.71 & $0.3579 * * *$ & 5.44 & & & & \\
\hline CONS_RANK & & & & & $0.7403 * * *$ & 5.54 & $0.3318 * * *$ & 5.05 \\
\hline $\mathrm{DAC}_{\mathrm{it}}-$ & 0.1311 & 0.61 & $0.6788 * * *$ & 4.12 & 0.1177 & 0.55 & $0.6835 * * *$ & 4.15 \\
\hline $\operatorname{LOSS}_{\mathrm{it}}$ & $0.3085^{* *}$ & 3.2 & $0.4133 * * *$ & 6.71 & $0.2807 * *$ & 2.92 & $0.4172 * * *$ & 6.77 \\
\hline FRAUD $_{\text {it }}$ & 0.06 & 0.67 & -0.0234 & -0.52 & 0.0797 & 0.9 & -0.0187 & -0.42 \\
\hline Constant & $0.0301 * * *$ & 9.16 & $0.0305 * * *$ & 25.22 & $0.0295 * * *$ & 9.03 & $0.0306 * * *$ & 25.28 \\
\hline Year-fixed effects & Yes & & Yes & & Yes & & Yes & \\
\hline Industry-fixed effects & Yes & & Yes & & Yes & & Yes & \\
\hline Observations & 765 & & 2,870 & & 765 & & 2,870 & \\
\hline Adjusted $\mathrm{R}^{2}$ & 0.1794 & & 0.0793 & & 0.1888 & & 0.0779 & \\
\hline \multicolumn{9}{|l|}{ F-test for difference in } \\
\hline coefficient $\beta_{1}$ between & \multicolumn{4}{|c|}{ [1] vs [2] } & \multicolumn{4}{|c|}{ [3] vs [4] } \\
\hline F-statistic & \multicolumn{4}{|c|}{3.51} & \multicolumn{4}{|c|}{6.70} \\
\hline P-value & \multicolumn{4}{|c|}{0.0610} & \multicolumn{4}{|c|}{0.0096} \\
\hline
\end{tabular}




\section{Table 8: Additional analysis: financial statement conformity to Benford's Law}

Pane A reports findings of KS tests for conformity to Benford's Law of first digits of financial statement items of UK listed companies from 2005 to 2012. We calculate the KS statistic as specified in equation (6). The critical value (test value) used to test whether a data set conforms to Benford's Law at the $5 \%$ level of significance is $1.36 / \sqrt{\mathrm{P}}$, where $\mathrm{P}$ is the total number of first digits (Amiram et al., 2015). If the KS statistic of a company in a year is less than the test value, the distribution of the first digits conforms to Benford's Law.

Panel B reports the aggregate FSD for the entire market of the sample. The table shows the first digits being analysed, expected frequencies of the first digits following Benford's Law, observed (actual) frequencies of the first digits, deviations of the first digits from Benford's Law, where deviations are defined as the absolute values of the observed frequencies minus the expected frequencies. FSD is the sum of all deviations divided by nine. Definitions of variables are in the Appendix.

Panel A: Conformity to Benford's Law at the firm-specific level

\begin{tabular}{lcc}
\hline & $\begin{array}{c}\text { Number of firm-year } \\
\text { observations }\end{array}$ & Percentage \\
\hline Conformity & 9,130 & $90.86 \%$ \\
Non-Conformity & 918 & $9.14 \%$ \\
Total & 10,048 & $100.00 \%$
\end{tabular}

Panel B: Conformity to Benford's Law at the market level

\begin{tabular}{|c|c|c|c|c|}
\hline First digit & $\begin{array}{c}\text { Number of first } \\
\text { digit }\end{array}$ & $\begin{array}{c}\text { Expected } \\
\text { frequency }\end{array}$ & $\begin{array}{c}\text { Observed } \\
\text { frequency }\end{array}$ & Deviation \\
\hline [1] & {$[2]$} & [3] & [4] & [5] \\
\hline 1 & 218,700 & 0.3010 & 0.3033 & 0.0023 \\
\hline 2 & 127,672 & 0.1761 & 0.1771 & 0.0010 \\
\hline 3 & 90,719 & 0.1249 & 0.1258 & 0.0009 \\
\hline 4 & 69,400 & 0.0969 & 0.0963 & 0.0007 \\
\hline 5 & 57,485 & 0.0792 & 0.0797 & 0.0005 \\
\hline 6 & 47,424 & 0.0670 & 0.0658 & 0.0012 \\
\hline 7 & 41,411 & 0.0580 & 0.0574 & 0.0006 \\
\hline 8 & 36,185 & 0.0512 & 0.0502 & 0.0010 \\
\hline 9 & 32,031 & 0.0458 & 0.0444 & 0.0013 \\
\hline Total & 721,027 & 1.0000 & 1.0000 & 0.0094 \\
\hline FSD & & & & 0.0010 \\
\hline
\end{tabular}

